\title{
Numerical Taxonomic Analysis of Some Slowly Growing Mycobacteria Using Hypothetical Median Strain Patterns
}

\author{
By G. P. KUBICA \\ Trudeau Institute, Inc., P.O. Box 59, Saranac Lake, New York, I 2983 \\ AND VELLA A. SILCOX \\ Mycobacteriology Unit, Center for Disease Control, Atlanta, Georgia, 30333, U.S.A.
}

(Received 30 June 1972; revised 29 August 1972)

SUMMARY

The reactions of 1498 isolates of slowly growing mycobacteria in 50 character states have been compared to those of $I 7$ hypothetical median strain patterns. The establishment of intra- and intertaxon matching values for clusters so generated, allowed certain aggregates of taxa to be recognized for which a conventional $n \times n$ matching matrix might provide more clear cut taxonomic definition of species. Those species which are clearly distinct from the others include Mycobacterium tuberculosis, $M$. bovis, M. kansasii, $M$. flavescens, $M$. xenopi and $M$. gastri. Problems still exist regarding the precise separation of taxa within Runyon Groups II (M. scrofulaceum, M. gordonae and III B) and Group III ( $M$. avium-M. intracellulare and $M$. terrae-M. nonchromogenicum-M. novum-M. triviale). These latter are discussed.

\section{INTRODUCTION}

The application of computer technology has enabled the sorting (by means of $n \times n$ matching matrices) of mycobacteria into clusters having high degrees of internal similarity (Bojalil \& Cerbon, I96I ; Cerbon \& Bojalil, I96I ; Bojalil, Cerbon \& Trujillo, I962; Tsukamura, 1966; Kubica et al. 1970). Because of technical problems in handling excessively large $n \times n$ tables of similarities, early computer studies were limited in the numbers of cultures examined. Such cultures must therefore be representative of the thousands of strains of mycobacteria that pass through individual clinical laboratories each year. Several investigators (Wayne, 1966; Kestle, Abbott \& Kubica, 1967; Wayne, Doubek \& Diaz, 1967; Tsukamura \& Mizuno, I968; Kubica, I973) soon adopted the procedure of comparing hundreds, even thousands, of strains of mycobacteria to previously established 'hypothetical median strains' (Liston, Wiebe \& Colwell, 1963) of mycobacteria. This approach, which has been discussed by Wayne (I 967 ), has enabled examination and sorting of large numbers of strains with the following aims in mind: (i) to determine those clusters which already are very homogeneous (i.e. have high internal similarity and low intertaxon similarities), and probably warranting of species status; (ii) to verify the hypothetical median strain (HMS) of such clusters, and to select therefrom a few highly reliable tests which may be valuable to the clinical laboratories; and (iii) to ascertain which clusters (because of low internal similarities and/or high intertaxon similarities) are in need of more critical examination by conventional $n \times n$ analyses (Lockhart \& Liston, 1970).

The present study was concerned with the comparison of a large number of slowly growing mycobacteria to $17 \mathrm{HMS}$ patterns in the hope of better defining those clusters of organisms in need of more definitive examination. 
Table I. Properties determined for the test organisms

\begin{tabular}{lc}
\multicolumn{1}{c}{ Properties } & $\begin{array}{c}\text { Total } \\
\text { character } \\
\text { states }\end{array}$ \\
Culture characteristics & \\
Growth rate & 2 \\
Pigment & 3 \\
Colonial morphology & 3 \\
Temperatures of growth $\left(22,35,40{ }^{\circ} \mathrm{C}\right)$ & 3 \\
Biochemistry & \\
Arylsulphatase & 3 \\
Catalase & 3 \\
Niacin & I \\
Nitrate reductase & 2 \\
Tellurite reduction & 3 \\
Tween hydrolysis & 2 \\
Tween opacity & 2 \\
Growth inhibitory media & \\
Corn-meal agar & \\
Dye containing media $(6)$ & I \\
Nicotinamide, $0.5 \%$ & 6 \\
Sodium chloride, $5 \%$ & I \\
Sodium nitrite & I \\
Sodium oleate & 2 \\
Triphenyltetrazolium chloride & 3 \\
Antimicrobial susceptibility tests & I \\
Amithiazone; $p$-aminosalicylate; thipohen- & \\
2-carboxylic acid & \\
Isoniazid & \\
Streptomycin & 3 \\
\end{tabular}

\section{METHODS}

The hypothetical median strain (HMS) patterns for 13 species of mycobacteria had been established in earlier studies (Kestle et al. 1967; Kubica et al. 1970). In addition, four other HMS patterns were established: (i) as the work of Kubica, Kim \& Dunbar (1972) had shown the isoniazid resistant (INH-R) strains of Mycobacterium tuberculosis to have several test reactions at variance from those of the drug susceptible tubercle bacilli, a separate HMS was established for the INH-R $M$. tuberculosis; (ii) using the same philosophy, a separate HMS was also prepared for INH-R $M$. bovis; (iii) I 2 strains identified as $M$. flavescens were used to establish the HMS for this taxon; (iv) 35 organisms received under the designation Group III B (Lewis, Lasché, Armstrong \& Dunbar, 1960) were used to establish an HMS for this organism, since there was some suggestion that this might be a separate taxon.

Fifty test character states were used to examine the cultures (Table I). With the exception of pigment production in the dark and rate of growth, these characters were described previously (Kestle et al. 1967).

A total of 1498 isolates of slowly growing mycobacteria was examined using the 50 character states. The assembled data were coded in binary form (i.e. o or I) for computer analysis and every strain was then compared to each of the 17 HMS patterns. Both positive and negative matches were recorded and the strains were clustered according to highest percentage match ( $\% \mathrm{M}$ or $\mathrm{M}$ value) for one of the HMS patterns. For each cluster the intrataxon $M$ value (Mi) was determined by averaging all the $M$ values for the cluster. Using the 
Table 2. Similarity matrix of 17 hypothetical median strains of slowly growing mycobacteria*

Taxon designation

\begin{tabular}{|c|c|c|c|c|c|c|c|c|c|c|c|c|c|c|c|c|c|}
\hline $\begin{array}{l}\text { Micobacterium tuberculosi } \\
\text { (sensitive) }\end{array}$ & $137+$ & (94) & & & & & & & & & & & & & & & \\
\hline $\begin{array}{l}\text { M. tuberculosis } \\
\text { (INH-resistant) }\end{array}$ & 71 & 88 & (90) & & & & & & & & & & & & & & \\
\hline M. hotis (sensitive) & 27 & 88 & 75 & $(94)$ & & & & & & & & & & & & & \\
\hline$M$. boris (INH-resistant) & 10 & 75 & 75 & 831 & $(91)$ & & & & & & & & & & & & \\
\hline M. kansasii & 137 & 65 & 69 & 60 & 52( & (91) & & & & & & & & & & & \\
\hline M. scrofulaceum & 119 & 46 & 58 & 50 & 54 & 60 & $(88)$ & & & & & & & & & & \\
\hline $\bar{M}$ gordonae & 158 & 44 & 48 & 52 & 56 & 67 & 81 & (87) & & & & & & & & & \\
\hline .IIIB' & 108 & 44 & 48 & 52 & 56 & 63 & 81 & 92 & $(86)$ & & & & & & & & \\
\hline M. flarescens & 12 & 65 & 56 & 60 & 52 & 63 & 56 & 71 & 63 & (83) & & & & & & & \\
\hline M. arium & 130 & 54 & 63 & 58 & 58 & 56 & 79 & 69 & 77 & 52 & $(89)$ & & & & & & \\
\hline M. intracellulare & 255 & 44 & 56 & 48 & 52 & 50 & 85 & 67 & 71 & 50 & 90 & (93) & & & & & \\
\hline M. xenopi & 25 & 69 & 69 & 69 & 69 & 63 & 69 & 63 & 67 & 63 & 73 & 67 & $(81)$ & & & & \\
\hline M. terrae & 87 & 46 & 54 & 42 & 46 & 65 & 79 & 81 & 77 & 69 & 71 & 77 & 60 & $(88)$ & & & \\
\hline M. nonchromogenicum & $4 !$ & 50 & 54 & 46 & 45 & 65 & 75 & 81 & 73 & 73 & 67 & 73 & 56 & 96 & $(89)$ & & \\
\hline M. norum & 39 & 56 & 65 & 52 & 52 & 71 & 69 & 79 & 71 & 67 & 69 & 67 & 54 & 90 & 90 & $(88)$ & \\
\hline M. triviale & 34 & 54 & 58 & 54 & 54 & 56 & 58 & 69 & 65 & 73 & 54 & 56 & 56 & 79 & 79 & 81 & (91) \\
\hline$M$. gastri & 22 & 67 & 58 & 75 & 63 & 73 & 58 & 73 & 69 & 65 & 6.3 & 56 & 65 & 6.3 & 67 & 65 & $58(94)$ \\
\hline
\end{tabular}

* Matching scores are expressed as percentages. Numbers in parentheses represent mean intrataxon M score for the cluster. Clusters which demonstrate high intertaxon $\mathbf{M}$ values are indicated by bold lines.

$\dagger$ Numbers after taxon names indicate number of strains examined.

first $\mathrm{I} 340$ cultures examined, histograms were prepared against each of the $\mathrm{I} 7$ median strains to depict visually the distribution of homologous and heterologous cultures on the basis of $M$ values. If a strain showed the same $M$ value for more than one HMS, it was excluded from any subsequent $\mathrm{Mi}$ calculations but was included in the histograms as an aid in determining closely related clusters. In the final analysis there were 86 strains that exhibited the same $\% \mathrm{M}$ for two or more HMS patterns, thus only I4I 2 of the cultures examined were used in calculating the Mi values (Table 2). Comparison of the reaction patterns of all HMS strains with one another enabled the establishment of the intertaxon matching scores (see also Table 2).

\section{RESULTS}

Ten representative histograms, depicting both well characterized and poorly defined clusters, are shown in Fig. I and 2. Some recognized and accepted species of mycobacteria present homogeneous clusters (Fig. I), whereas others are clearly in need of better definition (Fig. 2). Organisms which exhibit the highest $\mathrm{M}$ value to the HMS of Mycobacterium kansasi $i$ and $M$. gastri are uniformly distinct from all other mycobacteria (Fig. $\mathrm{I} a, b$ ). These histograms are virtually bimodal with little overlap of heterologous organisms. Fig. I $(c)$ and (d) are similar; however, most notable here is the downward displacement (about $6 \%$ in intertaxon value; see Table 2) of the INH-R strains of $M$. tuberculosis when compared to the HMS of the drug-susceptible representatives of this taxon. While this slight displace- 

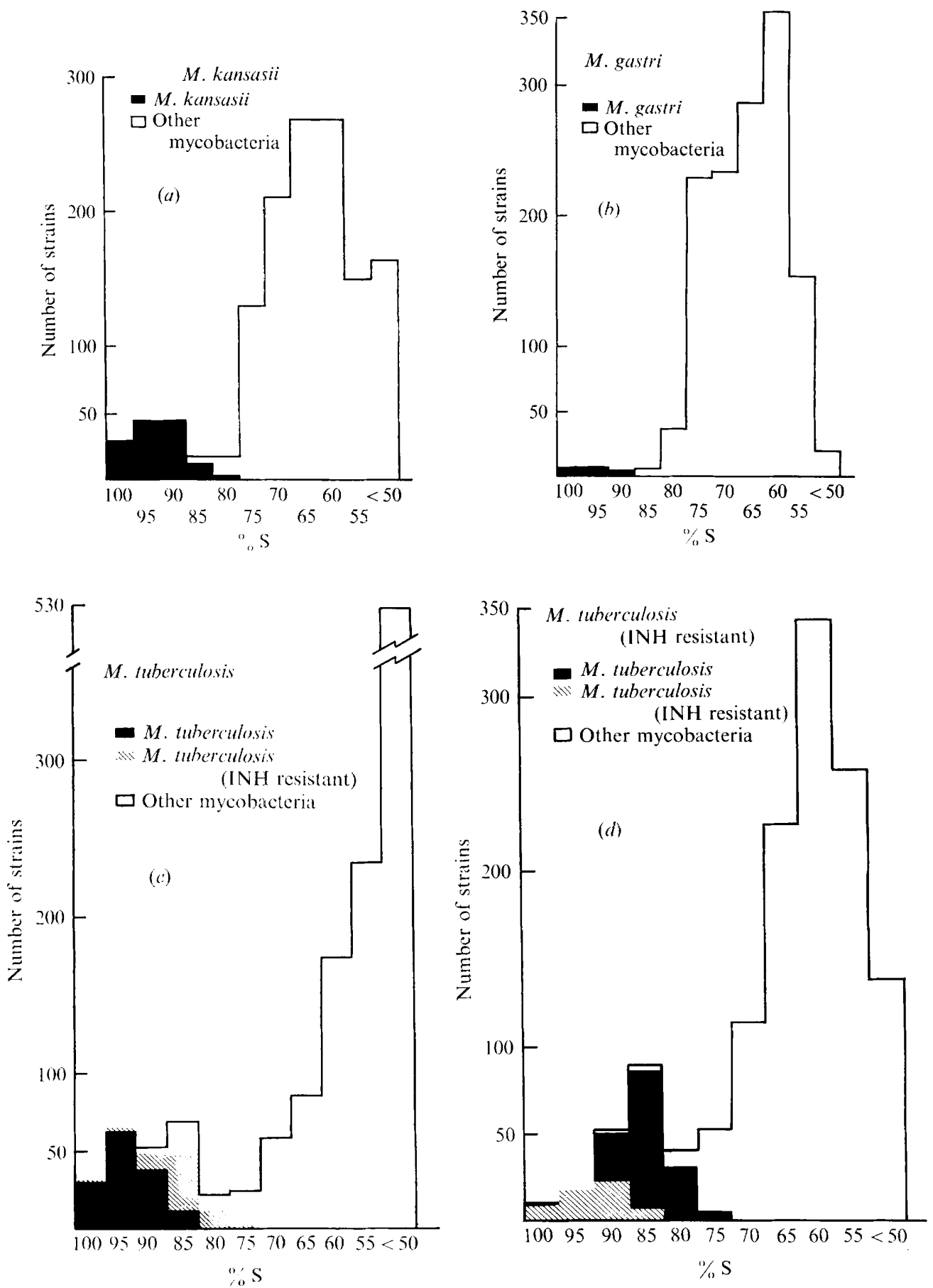

Fig. I $(a)-(d)$. For legend see facing page. 

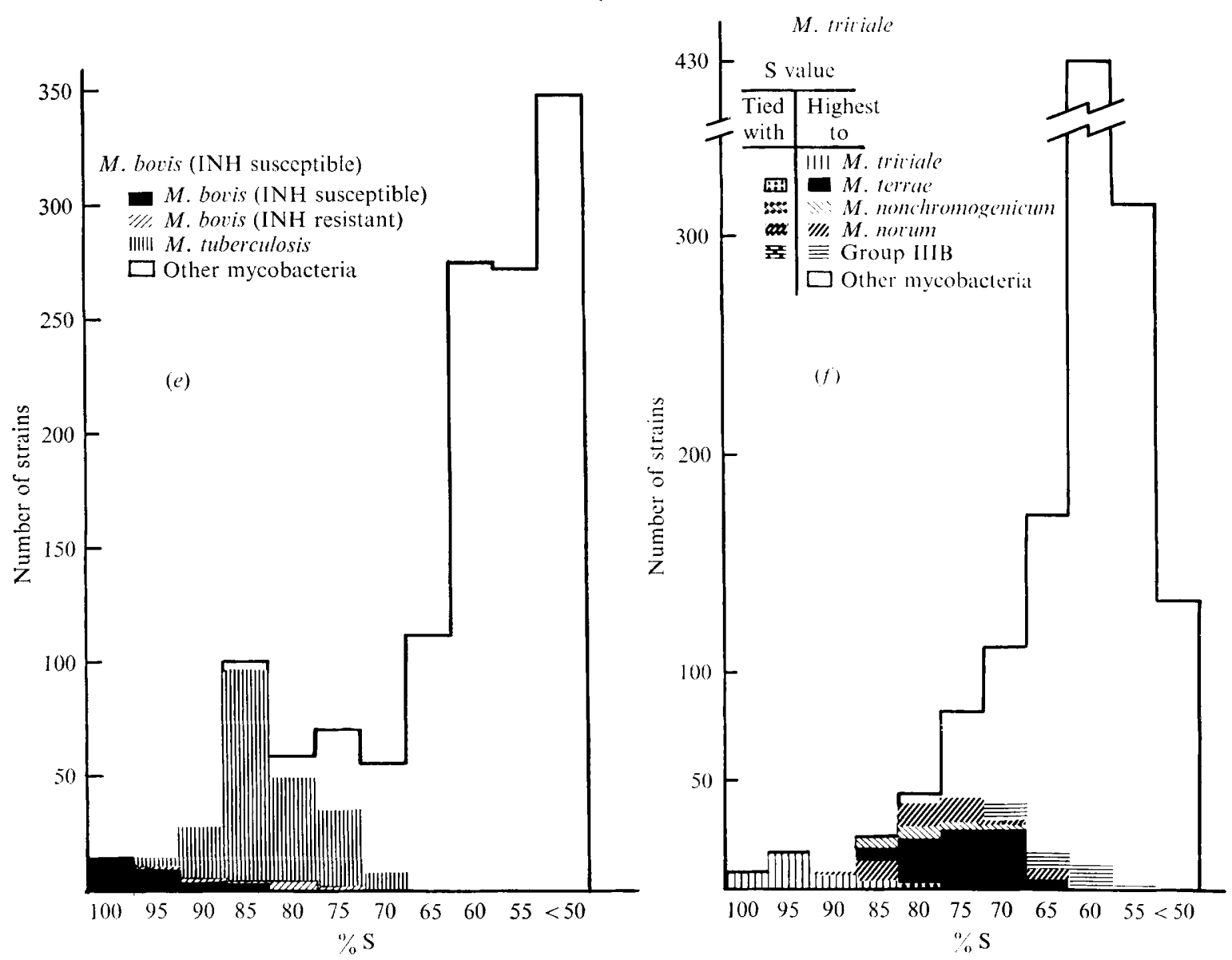

Fig. I $(e),(f)$.

Fig. I. Histograms showing the relationship of 1340 strains of slowly growing mycobacteria to the HMS patterns of (a) Mycobacterium kansasii; (b) M. gastri; (c) M. tuberculosis; (d) M. tuberculosis (INH-resistant); (e) M. bovis (INH susceptible); and $(f) M$. triviale.

ment is not sufficient to exclude INH-R strains from the taxon $M$. tuberculosis, it does reveal a close relationship of this species with $M$. bovis (see also Fig. I (e) and Table 2), a view earlier expressed by Wayne (I964). The 50 character states here employed had earlier been chosen for a general taxonomic study of all species of mycobacteria, and were not particularly selected with the point to strengthen the separation of $M$. tuberculosis from $M$. bovis, for indeed an appropriate selection of tests can readily facilitate such a distinction (Runyon et al. 1967; Wayne \& Doubek, I968; Kubica, 1973; Pattyn \& Portaels, I972).

The cluster labelled Mycobacterium triviale (Kubica et al. 1970) is taxonomically distinct from all other mycobacteria (Fig. I $f$ ). As Tsukamura \& Mizuno (I969) suggested that $M$. triviale is a variety of $M$. nonchromogenicum (Tsukamura, 1965), the $M$ values of a number of culturally similar, non-pigmented slowly growing mycobacteria for the HMS of $M$. trivale are segregated in Fig. $\mathrm{I}(f)$ for comparison. From this Figure and the data in Table 2, $M$. triviale may be distinguished from the other slowly growing non-pigmented mycobacteria using these 50 character states. This is further elaborated in the Discussion.

With some of the problem 'clusters' which still need to be resolved (Fig. 2), 


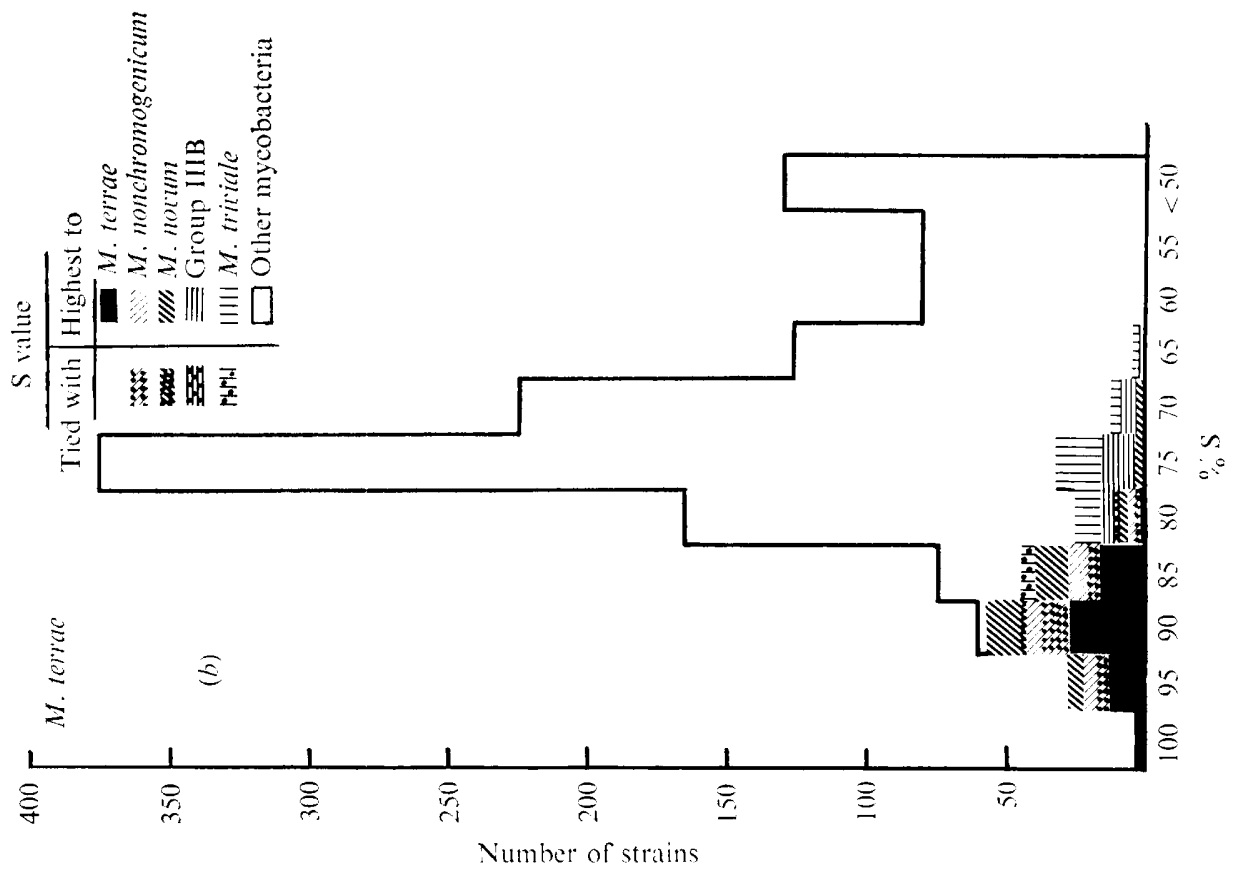

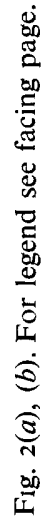

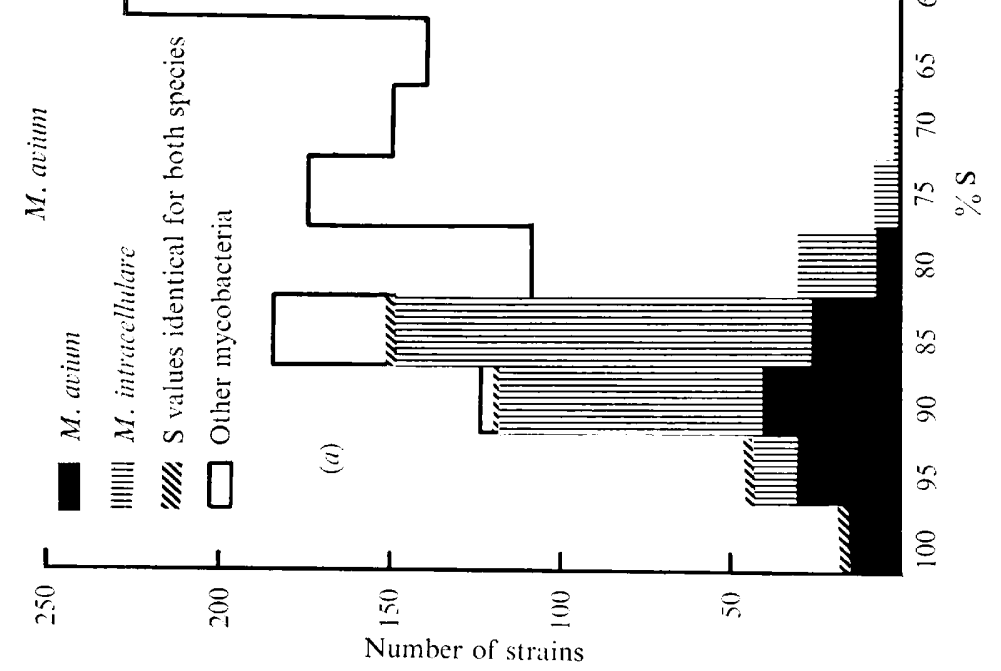




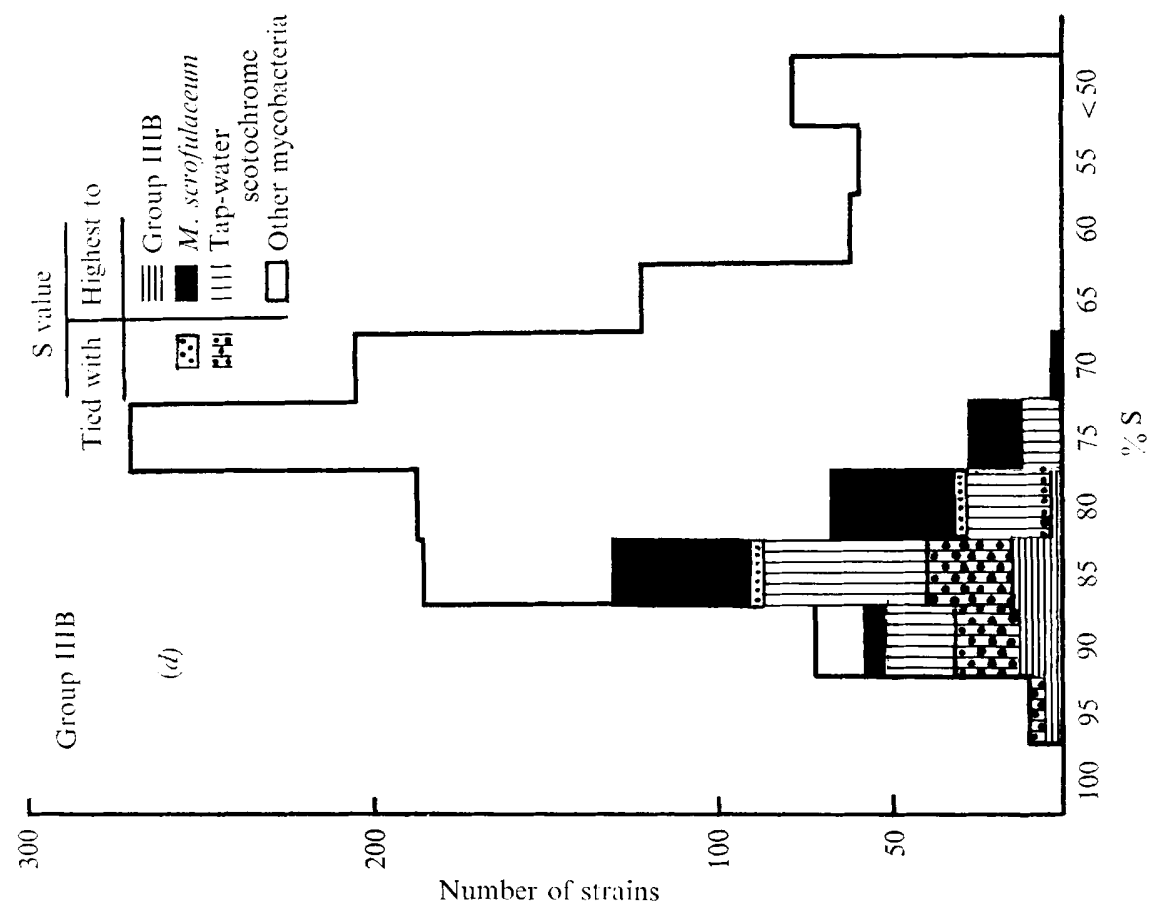

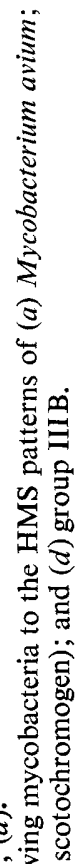

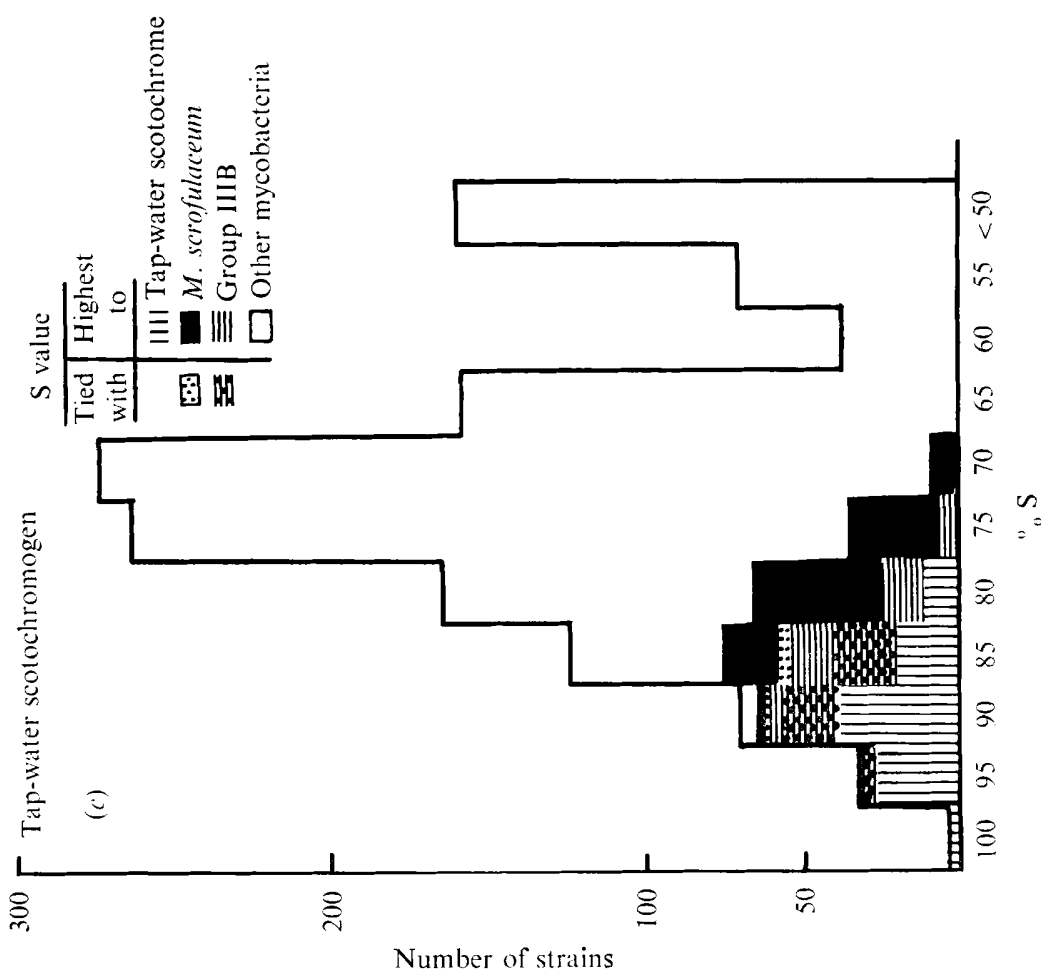

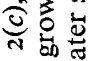

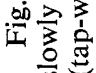


Mycobacterium intracellulare has a very close similarity for the HMS of M. avium (Fig. $2 a$ ). The very close intertaxon similarity of these two clusters $(90 \%$; see Table 2$)$ lends support to Wayne's (1967) suggestion that these two taxa probably represent variants of the same species.

Fig. 2(b) shows the distribution of $\mathrm{M}$ values of $\mathrm{I} 340$ mycobacteria for the HMS of Mycobacterium terrae Wayne (Wayne, 1966). Because of the close cultural similarity of other non-pigmented slowly growing mycobacteria of Runyon Group III (Wayne, Runyon \& Kubica, I969) to $M$. terrae, these have been specifically identified in Fig. $2(b)$ to enable a better understanding of the interrelationships of these taxa. Mycobacterium triviale and the cluster labelled III B are obviously unlike $M$. terrae, since the histogram shows them to have a similarity to $M$. terrae ranging from 65 to $80 \%$, with an intertaxon value of less than $80 \%$, for both taxa (see Table 2). On the other hand, M. nonchromogenicum and $M$. novum appear much more similar to $M$. terrae, revealing intertaxon similarities of $96 \%$ and $90 \%$ respectively (see Fig. $2(b)$ and Table 2 ).

Because of their apparent dissimilarity to any of the Runyon Group III organisms (Fig. I $(f), 2(b)$ ), the III B organisms were next compared to some of the culturally similar pigmented organisms of Runyon Group II (Wayne et al. 1969). The distribution of mycobacteria around the HMS of Mycobacterium gordonae (Wayne, 1970), called 'tap-water scotochromogen' makes it evident that the III B organisms are similar to $M$. gordonae, with many of them exhibiting tied $M$ values for this organism and their own HMS pattern (Fig. 2c). To substantiate further the closer relationship of IIIB organisms to Runyon Group II as opposed to Runyon Group III, organisms identified as $M$. scrofulaceum, $M$. gordonae (tap-water scotochromogen) and IIIB were compared to the HMS of IIIB (see Fig. $2 d$ ). Again the overlapping $M$ value distributions in the histogram reaffirm the greater similarity of III B to the scotochromogenic slowly growing mycobacteria, while the intertaxon $\mathrm{M}$ values (Table 2) suggest most III B organisms to be more like $M$. gordonae.

A more critical examination of the relationship of taxa within those 'pooled-clusters', indicated by bold lines in Table 2 , is clearly needed.

\section{DISCUSSION}

These data confirm the earlier report (Kubica et al. 1972) that INH-R strains of Mycobacterium tuberculosis tend to form a homogeneous cluster whose intertaxon $\mathrm{M}$ value for the parent drug susceptible organisms is 5 to $6 \%$ below the Mi value of the latter. Such a cluster distribution, while clearly discernible in the histograms (Fig. I $c, d$ ) is not sufficient to cause any taxonomic confusion or even to suggest relegation of INH-R mutants to a different taxon. This observation with respect to INH-R strains also holds true in the taxon M. bovis.

Within the large group of scotochromogenic Runyon Group II organisms, we note an aggregation of three clusters: Mycobacterium scrofulaceum, M. gordonae and III B organisms. It appears the III B cluster is more closely related to $M$. gordonae ( $92 \%$ intertaxon $M$ value; see Table 2). While $M$. scrofulaceum and $M$. gordonae appear rather similar in this group of 50 character states, the recent report of Wayne et al. (I97I) reveals that the use of several additional differential tests clearly separates these two taxa, while the selection of several highly reliable tests makes the separation of these two species an easy matter for the clinical laboratory (Wayne \& Doubek, 1968; Kubica, I973; Pattyn \& Portaels, 1972). Nevertheless, a conventional $n \times n$ examination of randomly selected scotochromogens would be indicated for this aggregation of taxa. The recent report of Jenkins, Marks \& Schaefer (1972) has suggested that, on the basis of lipid chromatography, $M$. scrofulaceum and $M$. gordonae 
might be pigmented variants of $M$. intracellulare and certain non-pathogenic, non-pigmented Runyon Group III mycobacteria, respectively. The intertaxon $M$ values in Table 2 would support this contention. This is a matter which has concerned mycobacteriologists for many years. While the pooled data from Wayne et al. (197I) indicate that the use of 140 character states enabled separation of $M$. scrofulaceum from $M$. intracellulare, only a few of the eight individual participants who contributed taxonomic data to this study (Wayne et al. 197I) were able to clearly segregate these two species.

Within the Runyon Group III organisms are several aggregate groups of taxa for which $n \times n$ matching matrices might resolve some sticky taxonomic problems. The Mycobacterium avium-M. intracellulare assemblage in one such. While Runyon (1967) has put forth arguments to favour the distinction of the two species, and the serological studies of Schaefer (I968) and Yoder \& Schaefer (I97I) have supported this, this report would corroborate Wayne's (1967) observation that there is insufficient evidence to suggest the taxonomic segregation of $M$. avium from $M$. intracellulare. Rather, they appear to be host-adapted variants of the same species, having a number of distinctive serotypes.

Among the more commonly saprophytic taxa within Runyon Group III, the intertaxon $M$ values of Table 2 reveal a close relationship of Mycobacterium terrae, $M$. nonchromogenicum and $M$. novum, with some suggestion of a similarity of $M$. triviale to $M$. novum. This latter observation is contradictory to Tsukamura \& Mizuno's (1969) report that $M$. triviale is more similar to M. nonchromogenicum. Although Tsukamura \& Mizuno (I969) employed 99 test characters, it should be noted that well over $50 \%$ of these were common negative matches in tests which prove more valuable when dealing with the rapidly growing mycobacteria. Using tests of more definitive value for slowly growing mycobacteria, the uniqueness of $M$. triviale has been demonstrated (Kubica et al. 1970).

While many of these taxa may be justifiably amalgamated for purposes of the clinical diagnostic laboratory (e.g. Mycobacterium avium-M. intracellulare and $M$. terrae- $M$. nonchromogenicum-M. novum; see Wayne \& Doubek, I968; Kubica, 1973), it is important for taxonomic reasons that these species be precisely delineated. The successful application of the HMS patterns to large numbers of isolates has now enabled us to focus attention on those smaller aggregates for which conventional $n \times n$ matching matrices may provide us more valuable information.

The authors wish to thank Dr Elmer Hall, Department of Biometrics, Emory University, and Mr Grady Waters of the Center for Disease Control in Atlanta, Georgia, for their assistance in coding and programming of the data presented in this report.

\section{REFERENCES}

Bojalil, L. F. \& CerBon, J. (196I). Taxonomic analysis of nonpigmented, rapidly growing mycobacteria. Journal of Bacteriology 81, 338-345.

Bojalil, L. F., Cerbon, J. \& Trujlllo, A. (I962). Adansonian classification of mycobacteria. Journal of General Microbiology 28, 333-346.

Cerbon, J. \& Bojalil, L. F. (196I). Physiological relationships of rapidly growing mycobacteria - Adansonian classification. Journal of General Microbiology 25, 7-1 5.

Jenkins, P. A., MARKs, J. \& SchaEFer, W. B. (1972). Thin layer chromatography of mycobacterial lipids as an aid to classification: The scotochromogenic mycobacteria, including Mycobacterium scrofulaceum, M. xenopi, M. aquae, M. gordonae, M. flavescens. Tubercle 53, I 1 8-1 27.

Kestle, D. G., Аввотт, V. D. \& Kubica, G. P. (1967). Differential identification of mycobacteria. II. Subgroups of groups II and III (Runyon) with different clinical significance. American Review of Respiratory Disease 95, 104I-1052. 
KuBICA, G. P. (I973). Differential identification of mycobacteria. VII. Key features for identification of clinically significant mycobacteria. American Review of Respiratory Disease (in the press).

Kubica, G. P., KiM, T. H. \& Dunbar, F. P. (1972). Designation of strain $\mathrm{H}_{37} \mathrm{Rv}$ as the neotype of Mycobacterium tuberculosis. International Journal of Systematic Bacteriology 22, 99-106.

Kubica, G. P., Silcox, V. A., Kilburn, J. O., Smithwick, R. W., Beam, R. E., Jones, W. D., Jun. \& StottMEIER, K. D. (1970). Differential identification of mycobacteria. VI. Mycobacterium triviale Kubica sp.nov. International Journal of Systematic Bacteriology 20, I6I-174.

Lewis, A. G., Lasché, E. M., Armstrong, A. L. \& Dunbar, F. P. (1960). A clinical study of the chronic lung disease due to nonphotochromogenic acid-fast bacilli. Annals of Internal Medicine 53, 273-285.

Liston, J., Wiebe, W. \& Colwell, R. R. (1963). Quantitative approach to the study of bacterial species. Journal of Bacteriology 85, 106I-1070.

LockHART, W. R. \& Liston, J. (editors) (1970). Methods for Numerical Taxonomy. Bethesda, Maryland: American Society for Microbiology.

Pattyn, S. R. \& Portaels, F. (1972). Identification and clinical significance of mycobacteria. Zentralblatt für Bakteriologie und Hygiene (Abteilung I. Originale) A 219, I I4-140.

Runyon, E. H. (1967). Mycobacterium intracellulare. American Review of Respiratory Disease 95, 861-865.

Runyon, E. H., Bönicke, R., Buchanan, R. E., Hanks, J. H., Käppler, W., Karlson, A. G., Kleeberg, H. H., Kubica, G. P., Lind, A., Mitchison, D. A., Pattyn, S. R., Redmond, W. B., Schaefer, W. B., Smith, D. W., Takeya, K., Vollum, R. L., Wayne, L. G., Wolinsky, E. \& Youmans, G. P. (I967). Mycobacterium tuberculosis, $M$. bovis and $M$. microti species descriptions. Zentralblatt für Bakteriologie und Hygiene (Abteilung I. Originale) 204, 405-4I 3.

SCHAEFER, W. B. (1968). Incidence of the serotypes of Mycobacterium avium and atypical mycobacteria in human and animal diseases. American Review of Respiratory Disease 97, 18-23.

TsuKamURA, M. (1965). A group of mycobacteria from soil sources resembling nonphotochromogens (Group 3). (In Japanese.) Medicine and Biology 7r, I I - I I 3.

TsuKamura, M. (1966). Adansonian classification of mycobacteria. Journal of General Microbiology 45, 253-273.

Tsukamura, M. \& Mizuno, S. (1968). 'Hypothetical Mean Organisms' of mycobacteria. A study of classification of mycobacteria. Japanese Journal of Microbiology 12, 37I-384.

Tsukamura, M. \& Mizuno, S. (1969). Taxonomy of subgroup ' $V$ ' of the Group III nonphotochromogenic mycobacteria. (In Japanese.) Kekkaku 44, I3-1 7 .

WAYNE, L. G. (1964). The mycobacterial mystique: Deterrent to taxonomy. American Review of Respiratory Disease 90, 255-257.

WAYNE, L. G. (1966). Classification and identification of mycobacteria. III. Species within Group III. American Review of Respiratory Disease 93, 919-928.

WAYNE, L. G. (1967). Selection of characters for an Adansonian analysis of mycobacterial taxonomy. Journal of Bacteriology 93, $\mathrm{r} 382-\mathrm{I} 39 \mathrm{I}$.

WAYNE, L. G. (1970). On the identity of Mycobacterium gordonae Bojalil and the so-called tap-water scotochromogens. International Journal of Systematic Bacteriology 20, I49-1 53.

Wayne, L. G., Dietz, T. M., Gernez-Rieux, C., Jenkins, P. A., Käppler, W., Kubica, G. P., Kwapinski, J. B. G., Meissner, G., Pattyn, S. R., Runyon, E. H., Schröder, K. H., Silcox, V. A., Tacquet, A., TsuKamuRA, M. \& WolinsKy, E. (1971). A co-operative numerical analysis of scotochromogenic slowly growing mycobacteria. Journal of General Microbiology 66, 255-271.

WAYNE, L. G. \& DoubeK, J. R. (I968). Diagnostic key to mycobacteria encountered in clinical laboratories. Applied Microbiology I6, 925-93I.

WAyne, L. G., DoubeK, J. R. \& DiAz, G. A. (1967). Classification and Identification of mycobacteria. IV. Some important scotochromogens. American Review of Respiratory Disease 96, 88-195.

Wayne, L. G., Runyon, E. H. \& Kubica, G. P. (1969). Mycobacteria: a guide to nomenclatural usage. American Review of Respiratory Disease 100, 732-734.

Yoder, W. D. \& SCHAEFER, W. B. (I97I). Comparison of the seroagglutination test with the pathogenicity test in the chicken for the identification of Mycobacterium avium and Mycobacterium intracellulare. American Review of Respiratory Disease 103, 173-178. 